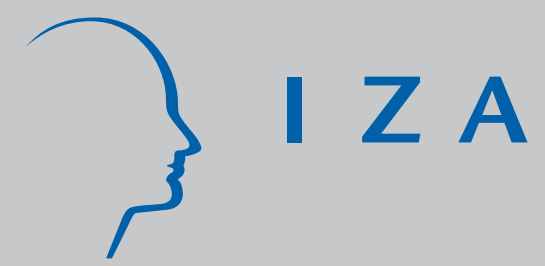

IZA DP No. 7346

Firm-Level Heterogeneity and the Decision to Export: A Real Option Approach

Wim Naudé

Thomas Gries

Natasa Bilkic

April 2013

Forschungsinstitut zur Zukunft der Arbeit Institute for the Study of Labor 


\title{
Firm-Level Heterogeneity and the Decision to Export: A Real Option Approach
}

\author{
Wim Naudé \\ MSM, UNU-MERIT, University of Maastricht \\ and IZA \\ Thomas Gries \\ CIE, University of Paderborn \\ Natasa Bilkic \\ CIE, University of Paderborn
}

Discussion Paper No. 7346

April 2013

IZA

P.O. Box 7240

53072 Bonn

Germany

Phone: +49-228-3894-0

Fax: +49-228-3894-180

E-mail: iza@iza.org

Any opinions expressed here are those of the author(s) and not those of IZA. Research published in this series may include views on policy, but the institute itself takes no institutional policy positions. The IZA research network is committed to the IZA Guiding Principles of Research Integrity.

The Institute for the Study of Labor (IZA) in Bonn is a local and virtual international research center and a place of communication between science, politics and business. IZA is an independent nonprofit organization supported by Deutsche Post Foundation. The center is associated with the University of Bonn and offers a stimulating research environment through its international network, workshops and conferences, data service, project support, research visits and doctoral program. IZA engages in (i) original and internationally competitive research in all fields of labor economics, (ii) development of policy concepts, and (iii) dissemination of research results and concepts to the interested public.

IZA Discussion Papers often represent preliminary work and are circulated to encourage discussion. Citation of such a paper should account for its provisional character. A revised version may be available directly from the author. 
IZA Discussion Paper No. 7346

April 2013

\section{ABSTRACT}

\section{Firm-Level Heterogeneity and the Decision to Export: A Real Option Approach}

In "new" new international trade theory, whether firms export or not are determined by their productivity. These models assume that firms enter a market to find their productivity levels revealed to them as in a lottery. In this paper we propose an alternative way to model whether firms export or not, namely as a firm-level decision akin to an investment decision with a real option value. We show that endogenizing the export decision is consistent with patterns of productivity and exporting reported in the empirical literature.

JEL Classification: D92, D81, L26, M13

Keywords: international new ventures, firm-level heterogeneity, start-ups, stochastic dynamic programming, trade, exports, productivity, real option theory, investment, firms, international entrepreneurship

Corresponding author:

Wim Naudé

Maastricht School of Management

University of Maastricht

P.O. Box 616

6200 MD Maastricht

The Netherlands

E-mail: naude@msm.nl 


\section{Firm-Level Heterogeneity and the Decision to Export: a Real Option Approach}

\section{Introduction}

According to "new" new trade theory (e.g. Bernard and Jensen, 1999;2004; Melitz, 2003) differences in export behavior are due to differences in firm-level productivity. To survive in domestic markets, firms need to be productive; however to export they need to be even more productive. This implies that productivity thresholds may exist according to which some firms will produce only for the domestic market, some will export and, in case of the most productive, will also invest abroad (Bernard et al., 2007; Chang and van Marrewijk, 2011; Greenaway and Kneller, 2007; Helpman, et al. 2004).

In earlier models a firm's productivity level is the outcome of a lottery, so that they faced "an exogenous ex-ante distribution of potential productivity levels" (Marin and Verdier, 2007: 4). Entrepreneurs are therefore ignorant $a$ priori about productivity levels of their firms before its start-up. Once they enter the market however, the outcome of the "productivity" lottery becomes known. In light of this information the firm will either then immediately exit, or produce only for the local market, or also export (and/or also invest abroad) depending on the realized productivity level.

The assumption of productivity lotteries is unfortunately inconsistent with a number of features on exporting behavior.

For one, it implies that firms self-select into exporting and that there is no learning-by-doing from exporting (e.g. Clerides et al., 1998). Productivity differences are only explained statically in its (fixed) levels and not growth rates. Second, it implies that all exporting firms are early exporters, or new international ventures ("born globals"). This is because once productivity lottery outcomes are known, firms immediately react either by quitting, exporting or not exporting. All exporting firms are therefore born-global firms in these models. They do not wait or learn or grow, but immediately sort themselves in export and non-exporting markets (or quit altogether). This is at variance with empirical evidence (see e.g. Wagner, 2007); indeed many if not most firms do not start exporting at or soon after their birth. The Johansen and Vahlne process (or stages) model of internationalization in business theory was based on the observation that older firms are more likely to export (Johansen and Vahlne, 1977). This makes intuitively sense if one accepts that exporting is a complex process requiring the prior development of key firm capabilities, including knowledge of foreign markets.

"New" new trade theory has largely ignored the direct implication for early exporting / born global firms. If there are early and late exporters as there clearly are in practice, what can we say or expect about their productivity levels? If productivity is not exogenously determined by a lottery, why do some 
firms export early and some late? Does the phenomenon of late exporters mean that there is some preparation (or "dressing up") period where firms can raise their productivity level? And what about early exporters - how do they achieve the threshold productivity if there is no productivity lottery - can they also "dress up" before the firm is started up, and what do we know about this latent entrepreneurial process?

Firms are very heterogeneous in terms of managerial ability, management effort, entrepreneurial orientation and in the degree to which new technology is adopted and whether and how much is invested in R\&D (e.g. Ceccagnoli, 2005). In contrast to the assumption in early "new "new international trade models, firms strategically invest in these aspects before entering international markets. Their productivity after market entry is therefore unlikely to be the outcome of a lottery, but more likely to be the result of firm-level strategic considerations. In contrast to the early "new "new international trade models causality runs from productivity to exporting (at both the intensive and extensive margins) but also the other way: firms can invest in their productivity or learn from exporting to become productive. And in contrast to theory, firms can be irregular exporters to the extent to which their (endogenous) productivity is affected by managerial ability and adoption of technology.

Until now these instances where theory and empirics differ have not received much attention in the "new" new international trade theory. Models of firmlevel heterogeneity ought not only to explain heterogeneity in terms of exporting, but also in terms of the age of exporting. When a firm starts exporting may not be a trivial question (Naudé and Rossouw, 2010). We know that timing issues are important in decision-making - for instance in investment decisions timing is central, as reflected in real option theory. Given significant fixed costs and learning, the decision whether and when to export are very similar to an investment decision. However, whereas in real option models timing is crucial because of characteristics of the external market, in the case of exporting the decision whether and when to export may depend on the characteristics of the firm.

In this paper we contribute to the "new " new trade theory by using real option theory to model the decision of entrepreneurs whether to start exporting simultaneously when they start up a firm, and to learn from exporting even when their productivity is lower than the threshold necessary to sustain successful exporting. The paper is structured as follows. In section 2 we propose a real option model to describe the decision to export. In section 3 we use this model to identify the the determinants of the timing of exporting. In section 4 we discuss some implications from the model and areas for further research and theorizing. Section 5 concludes. 


\section{A Real Option Model of Exporting}

\subsection{Basic Idea}

A firm's productivity level is not the outcome of a lottery. Firms will actively try to improve their productivity levels before exporting. Constantini and Melitz (2008) describe firms as "dressing up " for exporting by adopting better technology - e.g. through R\&D expenditures. Castellani and Giovannetti (2010) find empirical evidence for the notion of "dressing up" from a sample of Italian firms. This "dressing up " phase may in many respects be akin to the investment decision under uncertainty, as modelled by Dixit (1989). Although Dixit (1989) did not explicitly consider export market entry, but rather the decision of an existing firm to invest or not to invest in a new project, one could interpret " project " to also refer to the decision to export or not. Dixit (1989) showed that if the returns for a risk-neutral firm of investing in a new project are subject to uncertainty and there is even a small amount of sunk costs, it will be costly for firms to reverse their decision. In such cases the option to wait takes on a positive value. As such the decisions of a firm to export can be analyzed using the Dixit and Pindyck (1994) approach.

By applying this approach to exporting we are following a trend in the literature where real option theory is presently diffusing as a general decision theory into many fields. Including decisions on international ventures like in Gilroy and Lucas (2006), or Yalcin (2009). An important advantage of this approach is the evaluation of uncertainty and costliness of reversing a decision. While in these models so far the investment decsions is determined by waiting for an exogenous improvement of uncertain conditions to start the venture, our paper suggests an active process of investment to generate the required productivity growth endogenously. This endogenous and even time consuming investment in the firms productivity to imporve competitiveness eventually allows for international market entry. As we show in the next subsection, uncertainty and irreversibility are key characteristics of the export market entry decision. However, entrepreneurs are not just wainting for things to happen, but they actively invest in their ideas, even if the investment process takes a while and accumulates costs.

\subsection{Export Market Entry under Uncertainty}

In the sub-sections that follow we start out by describing the uncertain future faced by the firm when contemplating exporting as consisting of various profit streams subject to different stochastic processes. We then derive a price or profit threshold at which it is optimal for a latent exporting firm to conclude its preparation and investment period when it developed its managerial and technological profile (gestation) and enter the market (become an international exporter). Identifying this profit threshold generated by learning and preparation - raising productivity - allow us to then determine the expected duration of the "dressing up" period, and hence to endogenously determine when 
a firm would enter export markets. The sorting of firms into exporters and nonexporters according to a prioductivity lottery is thus replaced by an endogenous entry decision, and this entry decision is a result of an endogenous investment, productivity improving and learning process. The timing decision as modelled has three components, namely (i) the accumulated investment cost and benefits of dressing up for international market entry, the (ii) value of exporting (the expected net value of uncertain profits) and (iii) the option value of entering the marketat a later date, which includes the possibility of further improving the quality of the product. We discuss each of these three components.

\subsection{1 (i) Dressing Up and Preparing for Export Period (Conception and Gestation)}

There are sunk costs to exporting, consisting of amongst others market research, identification and evaluation of export opportunities, establishment of networks, and improving the quality of the product or service so that it can match international standards. Let $C_{i}$ represent these costs for a latent exporting firm $i$ in each period. These costs are heterogenous amongst firms to the extent that they have differing levels of managerial experience, entrepreneurial orientation and technological sophistication. Thus, at the end of the dressing up period, the same planning activities or objectives will have heterogenous costs for different firms. For simplicity we assume that these costs are constant for each new latent exporter ${ }^{1}$.

If we define the time at which a latent exporter perceives an opportunity of international market entry as $t=0$, the total investment or sunk cost is the sum of the costs of each period that the firm waits. The total costs or sunk investment is $I_{i}(T)$ which increases over time with each additional period of dressing up. Denoting the end of the dressing up phase by $T$, the current value of total sunk costs will be:

$$
I_{i}(T)=\int_{0}^{T} C_{i} e^{r(T-t)} d t+\bar{C}_{i},
$$

where $r$ is the risk-free interest rate. and $\bar{C}_{i}$ are the explicit eventual exports market entry costs. Although we abstract from taxes and subsidies, these could be included by correcting the effective interest rates $r$, the costs of preparing ${ }^{2}$ and the income streams for taxes.

Against theses total sunk costs one should consider that the dressing up phase generates benefits in the form of higher ex ante productivity. The latent export firm can observe the market performance of other products in the export market and the payoffs of product characteristics and qualities. This will allow the firm to judge the likely market reward for improving its product or service (further dressing up). Hence, the resources invested in the dressing up phase

\footnotetext{
${ }^{1}$ However, over time, for different products or as the firm climbs the product quality ladder, these costs may decrease as the firm benefits from learning by doing effects of exporting.

${ }^{2}$ If these costs are tax deductible.
} 


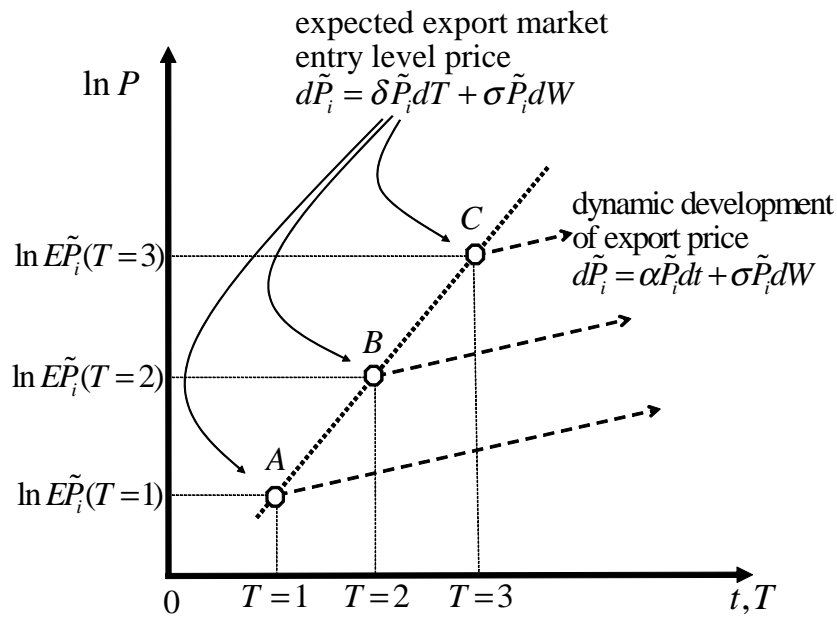

Figure 1: Expected export market entry level price and market price dynamics

may generate product and process improvements - or perceptions of improvements through marketing and brand-building - which could lead to an increase in firm-level productivity. This mechanism thus creates a potential link between product-improving investments and export market rewards. Having set out the above we can now describe the virtual stochastic path of the pre-export market value (price) while the firm is dressing up. In continuous time this random process can be described as a Brownian motion

$$
d \tilde{P}_{i}=\delta_{i} \tilde{P}_{i}+\sigma_{i} \tilde{P}_{i} d W \text { for } t<T .
$$

In $(2) \delta_{i}$ is the expected rate of reward in export markets due to a marginal improvement of a product $i$ during the dressing up phase. It is the marginal preexport market value differential with respect to product quality improvements (see in figure 1 the expected time path of the pre-entry market value described by the dotted line $)^{3}$. The expected marginal market reward $\delta_{i}$ must be large enough to compensate for the sunk costs $C_{i}$. Here $\sigma_{i}$ denotes a constant volatility and $d W$ he increments of the Wiener process.

\subsection{2 (ii) Value of Exporting}

Upon entry into export market $(t>T)$ the firm faces a stochastic revenue stream which can be described by an expected average growth rate subject to uncertainty. For simplicity we assume that each new exporter $i$ is a price-taker offering a single product or service. The price path of the product or service,

\footnotetext{
${ }^{3}$ For a formal discussion of the expected market value at market entry time $T$, see proposition 2 .
} 
$\left\{P_{i}(t)\right\}$ is described by the geometric Brownian motion

$$
d P_{i}=\alpha_{i} P_{i} d t+\sigma_{i} P_{i} d W \text { for } t>T,
$$

with a constant drift $\alpha_{i}$ and a constant volatility $\sigma_{i}$, where $\alpha_{i}, \sigma_{i}>0$. Here $d W$ denotes the increments of a standard Wiener process; and $\alpha_{i}$ describes the deterministic part of the process. For $\alpha_{i}>0 P_{i}$ will change at the rate $\alpha_{i}$. Depending on the product $i$ individual price profiles will have different growth patterns. With operating costs are constant the price profile will be identical to the profit profile. This simplifies matters as we do not need to distinguish further between market prices, revenues and profits and can refer merely to profits.

The latent exporter is assumed to be aware of the profits associated with each potential export product $i$. The dressing-up phase will be terminated and the firm will start exporting when a decision is taken to realize an expected export profit $\left\{P_{i}(t)\right\}$ associated with a particular quality of the export product $i$ and productivity level. In order to derive a rule for the expected time where it is optimal to start exporting, we have to determine the expected value of the risky profit stream for each potential export product $i$. Once a firm has started to export a particular product, we assume that the quality/ characteristics of the product or service and hence the profit profile are fixed. No other export opportunities can be chosen and the firm is locked in. The economic value of exporting for the firm consists solely of its future profits. For a risk neutral firm /entrepreneur the gross value of exporting $V_{i}^{\text {gross }}$ is given by the expected present value of the profit stream $\left\{P_{i}(t)\right\}$

$$
V_{i}^{\text {gross }}=E\left(\int_{T}^{\infty} P_{i} e^{-r(t-T)} d t\right)=\frac{P_{i}}{r-\alpha_{i}} ; \quad r>\alpha_{i},
$$

with $r$ being the risk-free interest rate as opportunity costs.

The firm is assumed to be immortal ${ }^{4}$ and the entrepreneur does not have the option of closing or selling his or her firm. Having defined the gross value of exporting we have to add that due to planning and preparation costs during the dressing up phase (1) the expected gross value of exporting has to be adjusted for sunk investment $I_{i}(t)$. Therefore the net value of the profit stream of exporting at the moment of market entry is

$$
V_{i}=V_{i}^{\text {gross }}-I_{i}(T)
$$

\subsection{3 (iii) Option Value of Waiting}

In addition to the expected net value of exporting the option value of waiting has to be considered. As long as the latent exporting firm delays market entry

\footnotetext{
${ }^{4}$ If we assume a finite lifetime, the end of the export project would be determined by the end of the life of the firm. This date however, may be random. While a random jump processes (modeled by Poisson processes) may be considered, addressing this issue would involve a substantial extension of our model. We leave the relaxation of this assumption for future work.
} 
it retains the option of market entry without the risk of failure and having to incur sunk costs. Waiting may open up additional opportunities which could not have been foreseen and realized otherwise.It may thus be beneficial to postpone exporting. Accounting for the option value $F$ for the Brownian motion (2, the Hamilton-Jacobi-Bellman equation holds:

$$
r F d t=E(d F) .
$$

This Hamilton-Jacobi-Bellman equation indicates that after a time interval of $d t$ the total expected return on exporting is equal to the expected rate of waiting.

\subsection{Market Entry}

For a firm the decision whether or not to enter the export market consists of evaluating the three elements introduced above, namely the start-up investment costs, the uncertainty of export revenues and the option value of waiting. Given the expected net value of the new export business (4), the option value $F_{i}$ of waiting can be determined by applying dynamic programming. Once the option value of waiting has been determined, the question whether or not to wait for another period will be determined by the solution to:

$$
\max \left\{V_{i}(T), F_{i}(T)\right\}
$$

As long as the option value of postponing market entry is higher than the value of realizing the uncertain revenue stream, the firm will opt for another period of waiting. In order to determine the price, and hence productivity level that triggers market entry we need to consider the standard conditions concerning a stochastic dynamic programming problem of the introduced structure. In addition to the Hamilton-Jacobi-Bellman equation for the option value $F_{i}$ and applying Ito's lemma to $d F_{i}$, we have to use the well known boundary conditions, namely (7), the value matching condition (8), and the smooth pasting condition (9)

$$
\begin{aligned}
F_{\tau}(0) & =0 \\
F_{i}\left(P^{*}\right) & =V_{i}^{\text {gross }}\left(P^{*}\right)-I_{i}(T) \quad \text { value matching condition } \\
\frac{d F_{i}\left(P^{*}\right)}{d P} & =\frac{d V_{i}\left(P^{*}\right)}{d P} \quad \text { smooth pasting condition }
\end{aligned}
$$

to solve for the threshold market price $P^{*}$. The setting of the decision problem implies that the value of the uncertain revenue stream must be worth the switch from waiting to exporting. Hence, the revenue level implied by the Brownian motion must be sufficiently high. This leads us to Proposition 1:

Proposition 1 For productivity improving investment costs of $C_{i}$ per period and sunk international market entry costs $\bar{C}_{i}$, a pre-export market value of product $i$ following the Brownian motion (2), and a revenue stream of product $i$ that 


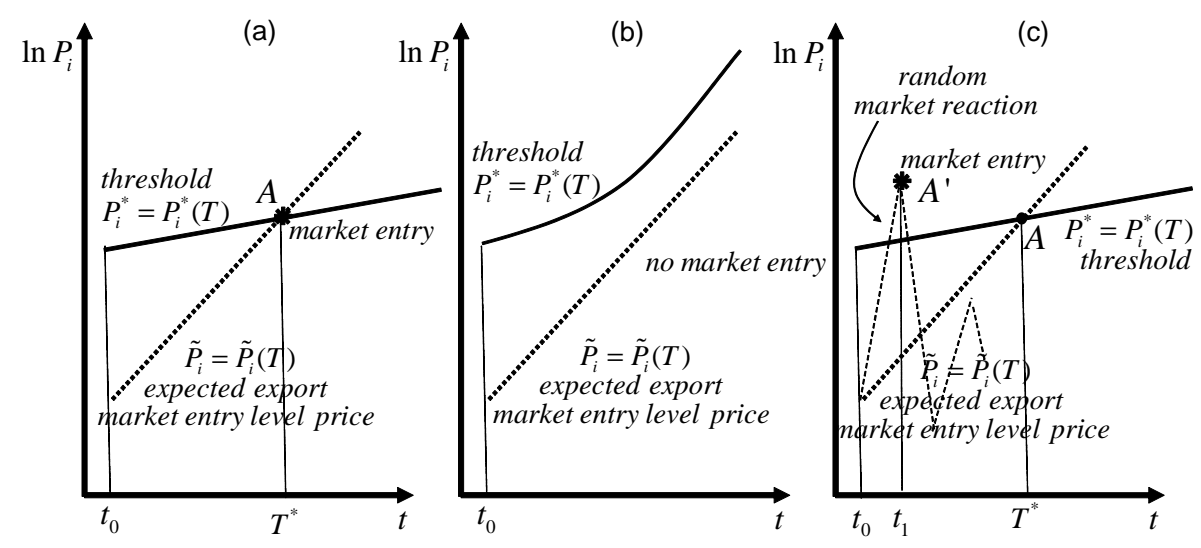

Figure 2: Threshold and Market Price Development

follows the Brownian motion (3) we can determine the price threshold $P_{i}^{*}(T)$ that would trigger exporting as

$$
\begin{aligned}
P_{i}^{*}(T) & =\frac{\lambda_{i}}{\lambda_{i}-1}\left(r-\alpha_{i}\right)\left[\frac{C_{i}}{r}\left(e^{r T}-1\right)+\bar{C}_{i}\right], \\
\text { with } \lambda & =\frac{1}{2}-\frac{\delta_{i}}{\sigma_{i}^{2}}+\sqrt{\left(\frac{1}{2}-\frac{\delta_{i}}{\sigma_{i}^{2}}\right)^{2}+\frac{2 r}{\sigma_{i}^{2}}} \\
\text { and } r & >\delta_{i}
\end{aligned}
$$

Proof: See Appendix 1.

Since each additional period of waiting increases the total start-up costs the entry-threshold becomes a function of $T$. To illustrate the threshold and its determinants figure 2 (panel a) considers the case of firm $i$. In figure 2 (panel a) the horizontal axis represents duration of planing $(T)$ and the vertical axis the natural $\log$ of the price (and revenue) level, $P_{i}$. In figure 2 (panel a) the threshold curve is increasing over time because waiting is linked to dressing up and improving productivity. The figure shows that an additional period of waiting drives up the threshold as the firm needs to be compensated by a higher market price when entering the market. As long as the reward from exporting from productivity-improving dressing up increases faster than the threshold of the firm, successful export market entry will be possible. The expected time to start exporting is then known. (figure 2 panel (a)). This discussion is elaborated below.

Once the firm is aware at which initial price level it should export the question is when this price will be observed. The time before entry can be used for product improvements as described by (2) so that the pre-export market 
value and revenue of the firm will increase with the length of the dressing up period as shown by the dotted line in figure 1 .

However, to determine the expected time of export market entry we need to introduce another concept. As the development of the pre-export (initial) market value is described by a random process (2), and the threshold will trigger the export market entry we are interested in the expected time when the threshold might be reached for the first time. This time is called the expected first passage time. Because the threshold is non-linear we introduce here an instrument which allows us to capture the non-linear development of the threshold, and which can be graphically illustrated. Specifically, for the random process $\tilde{P}_{i}$ (see (2)) we derive the expected first-time realization of a certain pre-export (initial) market value $\tilde{P}_{i, x}$ (given today's value $\tilde{P}_{i, 0}$ ). By using the Girsanov theorem we can derive the probability density function of $\tilde{T}_{i, x}$ or Inverse Gaussian Distribution. Because we can determine the expected time of the realization of each value $\tilde{P}_{i, x}>\tilde{P}_{i, 0}$ for the interval $\left.\left.\tilde{P}_{i, x} \in\right] \tilde{P}_{i, 0}, \infty\right]$ we can express the expected time of realization as a function of $\tilde{P}_{i, x} / \tilde{P}_{i, 0}$. This leads us to the next proposition:

Proposition 2 From the Brownian motion (2) we can derive the expected first time realization E $\tilde{T}$ of all pre-export (initial) market values $\tilde{P}_{i}>\tilde{P}_{i, 0}, \tilde{P}_{i} \in$ ]$\left.\tilde{P}_{i, 0}, \infty\right]$ as a function of $\tilde{P}_{i, x} / \tilde{P}_{i, 0}$, and hence determine the expected time until any pre-export (initial) market values $\tilde{P}_{i}$ is reached as

$$
E \tilde{T}_{i}=\frac{1}{\delta_{i}-\frac{1}{2} \sigma_{i}^{2}} \ln \left(\frac{\tilde{P}_{i}}{\tilde{P}_{i, 0}}\right)
$$

Proof. For a proof see Appendix 2.

This expected time of realization $E \tilde{T}_{i}$ of all pre-export (initial) market values of variation $i$ can be drawn as the $E \tilde{T}$-curve in figure 2 (panel a). As depicted in figure 2 (panel a) there are two pieces of information available to determine the first passage time and hence the expected time until exporting. First, the latent exporter knows the threshold $P_{i}^{*}(T)$ that would trigger market entry. Second, from the properties of the Brownian motion (2) the latent exporter knows the expected first-time realization $E \tilde{T}_{i}$ of each pre-start-up (initial) market value, that is the expected time when a certain market value $\tilde{P}_{i}$ is expected to be reached $E \tilde{T}_{i}$.

If the particular initial market value $\tilde{P}_{i}$ is expected to be reached at $E \tilde{T}_{i}$ and if $\tilde{P}_{i}$ matches the value of $P_{i}^{*}(T)$ at this particular time (for $T=E \tilde{T}_{i}$ ), we obtain the expected first passage time $T_{i}^{*}$. Hence, we can determine the expected duration of the dressing-up phase for each latent export firm $i$. The dressing up phase will end and exporting will start given the present expectations for the development of the market value (revenue) during the waiting period, and given expectations about the firm's export revenue profile. We can now derive the following proposition. 
Proposition 3 With the threshold $P_{i}^{*}(T)$ (see (10)), the expected realization of initial (pre-export) market values E $E \tilde{T}_{i}$ (see (13)), and condition (15) and (16) there exist an expected time of exporting $T_{i}^{*}=E(T)>0$ (first passage time); and for each vector $\left(\alpha_{i}, r_{i}, \sigma_{i}, T_{i}^{*}, C_{i}, \tilde{P}_{i}(0), \delta_{i}, \bar{C}_{i}\right)$ that fulfils (a) there is a marginal environment, such that $T_{i}^{*}$ is an implicit function of $\alpha_{i}, \sigma_{i}, C_{i}, \tilde{P}_{i}(0), \delta_{i}, \bar{C}_{i}$ and $r$.

$$
\begin{aligned}
& T_{i}^{*}=T_{i}^{*}\left(\alpha_{i}, \sigma_{i}, C_{i}, \tilde{P}_{i}(0), \delta_{i} r\right) \\
& \frac{\lambda}{\lambda-1}\left(r-\alpha_{i}\right) \bar{C}_{i}>\tilde{P}_{i}(0) \\
& \bar{C}_{i} r\left.>\bar{C}_{i} \delta_{i}>C 0\right)
\end{aligned}
$$

Proof. See Appendix 3.

In figure 2 (panel a) a higher level of the threshold compared to the expected realization of initial (pre-export) market value indicates that the firms ' efforts to develop the product and the firms productivity during the dressing up period (before $T_{i}^{*}$ ) are not yet sufficiently compensated by the current market value of the product. Hence the firm will not yet start exporting.If the market does not reward the costs of additional efforts sufficiently, market entry will not happen. This outcome is illustrated in figure 2 (panel b). The increasing slope of the threshold curve indicates that additional time and costs spent on product and process development and placement must be compensated by sufficiently increasing market rewards and hence a rising expected market price at market entry. In figure 2 (panel b) market rewards will not match the increase in the threshold. As a result there will be no intersect of the two curves and hence no exports.

However, the expected time of exporting $\left(T_{i}^{*}\right)$ is an indicator of what might happen in the future. In figure 2 (panel c) we draw the time path of the preexport expected market value of the product for the present state of information at time $t_{0}$ by the dotted line. Consequently, even if the firm expects to enter the foreign market at $T_{i}^{*}$, a randomly occurring incident in the market can push the pre-exporting expected market price so that the threshold is reached and the firm will start exporting. In figure 2 (panel c) this is displayed by the randomly upward shift of the realized market value at point $A^{\prime}$. The observed and hence realized market value exceeds the threshold at $t_{1}$ and hence trhe firm will start exporting at $t_{1}$ and not -as expected before- at $T^{*}$. It is easy to find illustrative examples for such an unexpected early export market entry and indeed we can posit that many international new ventures (INVs) or "born globals" may reflect unexpected early export market entry. If the firm is in a particular industry, e.g. in high-tech communications with rapid expansion in global consumer markets; or due if the firm is in a natural resource dependent 
industry where trade costs are high, a sudden decrease in trade costs will lead the firm to immediately start exporting. The entrepreneurial firm will take this randomly occurring opportunity at $t_{1}$ - no matter what it previously planned or expected.

\section{Determinants of Heterogeneity in Timing of Exporting}

Having outlined our model in the previous sections we now illustrate its comparativestatic properties and identify the determinants of heterogeneity in the timing of export market entry. More precisely we analyze the impact of (i) price uncertainty $\sigma_{i}$, (ii) expected profit growth $\alpha_{i}$ in the export market, (iii) the no-export profit level $\tilde{P}_{i}(0)$, and (iv) costs for dressing up $C_{i}$. As all these conditions are different for different industries and firms it can be expected that these firm, sector, or even country specific differences will lead to a different timing of market entry.

Figure 3 illustrates the reaction of export market entry when different parameters change.

(a)

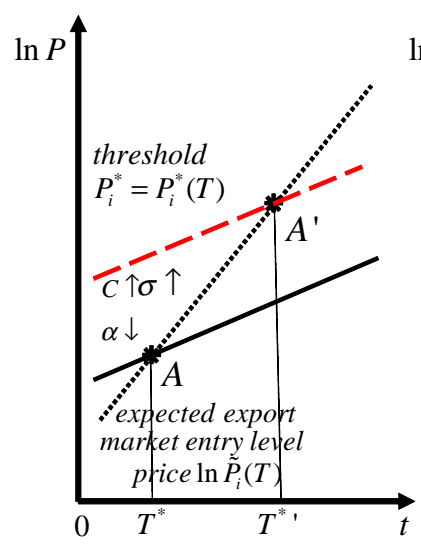

(b)

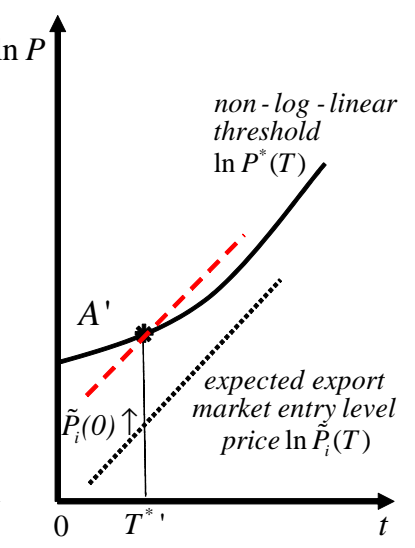

Changes in expected pre-export market evaluation

\section{(i) Price Uncertainty}

Proposition 4 With an increase in risk of the future earnings $\sigma_{i}$ expected ex- 
port market entry will be postponed, that is $T^{*}$ will increase,

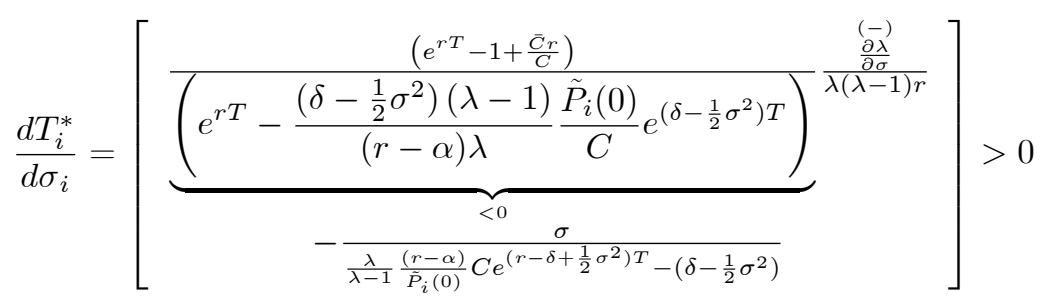

Proof. See Appendix 4.

The risk attached to profit - measured by the volatility of price - is expected to have a negative influence on the time of export market entry. Higher risk

will devalue the export earning stream and hence decrease the attractiveness of exporting. As long as additional net rewards of a longer dressing up period can compensate for the increase in the threshold,exports will still be pursued (see figure 3 (panel a). Higher risk will shift the threshold curve upwards and make a later market entry more attractive. Interestingly enough, this result is obtained even with risk neutral agents. We do not need to make any assumption about the utility function and risk aversion. The pure option value and the irreversibility include the effects of $\sigma_{i}$ in a similar way.

If from a sector or firm specific perspective exports become too risky there is no intersect in figure 3 (panel a) and the foreign market entry is not expected to take place. This may be the case in sectors with large international price volatility or highly unstable supply chain relations.

\section{(ii) Profit Growth}

Proposition 5 With an increase in the expected growth rate of profit in the export market expected time of exporting $T_{i}^{*}$ will move forward

$$
\frac{d T_{i}^{*}}{d \alpha_{i}}=\underbrace{\frac{\left[e^{r T}-1+\frac{\bar{C}_{i} r}{C_{i}}\right]}{\left(e^{r T}-\frac{\left(\delta_{i}-\frac{1}{2} \sigma_{i}^{2}\right)(\lambda-1)}{\left(r-\alpha_{i}\right) \lambda} \frac{\tilde{P}_{i}(0)}{C_{i}} e^{\left(\delta_{i}-\frac{1}{2} \sigma_{i}^{2}\right) T}\right)}}_{<0} \frac{1}{\left(r-\alpha_{i}\right) r}<0
$$

Proof. See Appendix 5.

Higher expected profit growth will shift the threshold curve in figure 3 (panel a) upwards and will make market entry more desirable. The latent exporter would like to enter the market earlier because he would like to gain sooner from the more rapid growth process. 


\section{(iii) Path Level of Pre-export Expected Market Value and Revenue}

Proposition 6 A rising level of the pre-export expected market value $\tilde{P}_{i}(0)$ of a potential export product $i$ will shorten the dressing up phase $T_{i}^{*}$

$$
\frac{d T_{i}^{*}}{d \tilde{P}_{i}(0)}=\underbrace{\frac{1}{\lambda-1}\left(r-\alpha_{i}\right) C_{i} e^{\left(r-\delta_{i}+\frac{1}{2} \sigma_{i}^{2}\right) T}-\left(\delta_{i}-\frac{1}{2} \sigma_{i}^{2}\right) \tilde{P}_{i}(0)}_{<0}<0 .
$$

Proof. See Appendix 6

$\tilde{P}_{i}(0)$ indicates the level of the path of the potential export market value (respectively profit) obtainable for product $i$ before export market entry when the opportunity is conceptualized at $t=0$. As barriers to export are important elements in this path we can directly see how such barriers affect the potential international market entry and the duration of the dressing up phase. While figure 3 panel (b) originally indicates no market entry due to high barriers, high export costs and low earnings (small entry level value $\tilde{P}_{i}(0)$ with a low level of the path of potential export earnings) a reduction of barriers shifts the potential earning path upwards. With an upward shift expiort market entry occurs earlier.

\section{(iv) Investment Cost for Getting Ready to Export}

Proposition 7 With higher costs of dressing up the expected time of exporting $T^{*}$ will be postponed:

$$
\frac{d T_{i}^{*}}{d C_{i}}=\underbrace{\left(e^{r T}-\frac{\left(\delta_{i}-\frac{1}{2} \sigma_{i}^{2}\right)(\lambda-1)}{\left(r-\alpha_{i}\right) \lambda} \frac{-\left[e^{r T}-1\right]}{C_{i}} e^{\left(\delta_{i}-\frac{1}{2} \sigma_{i}^{2}\right) T}\right)}_{<0} r C_{i} \tilde{P}_{i}(0 .
$$

Proof. See Appendix 7.

As $C_{i}$ denotes investment costs for export preparation, $\frac{d T^{*}}{d C}>0$ is the expected reaction. With increasing investment costs for dressing up the firm needs a compensation from the market. Therefore the required threshold curve shifts upwards in figure 3 (panel a). As long as the market would reward the outcome of the dressing up phase both curves would still intersect eventually. Hence higher dressing up costs for productivity enhancement would postpone exporting. However, this is the most simple linear case discussed in the proposition. If the marginal market reward is not sufficient (upper dashed line in figure 3 (panel a) increasing costs could make the project unfeasible. The shift in the threshold cannot be matched by the market reward and there will be no exporting for the particular firm. 


\section{Concluding Remarks}

On the firm-level there exist substantial heterogeneity in exporting behavior. This reflect productivity differences between firms. These differences are not however, due to a simple lottery. Firms can "dress up " and prepare to be export-ready. Such export readiness is however no simple decision. In this paper we argued that this decision is in many ways akin to an investment decision under uncertainty. Many firms never, or seldomly, reach productivity levels that allow them to enter export markets because it is more valuable to them to postpone exporting. This means that it is not only the decision to export wherein much heterogeneity on the firm-level is reflected, but also in the timing - the when - of exporting. This element of firm-level heterogeneity has largely been neglected in new new trade theory. Our paper is an attempt to rectify this neglect, by proposing a real options approach towards modelling the decision and timing to enter export markets.

Consideration of this element of firm-level heterogeneity means that while opening up or reducing trade barriers will lead to opportunities for firms these opportunities will not automatically and immediately translate into exports. Firms need to invest (or dress up) in their capability to export. Depending on the sector of production and/or the individual firm's ability resources are needed to enter the export market and realize gains from trade opportunities. At the micro level firm ability and access to these resources determine whether and how fast a firm enters international markets. This variation in ability and access to resources can explain observed productivity-export heterogeneity and illustrates why it is relatively more easy for some firms in a sector or country to export and why it is difficult or even impossible for others e.g. in developing economies. Hence, opening up can easily become an asymmetric event with respect to realizing potential gains from trade for different countries. Using the real option model derived in this paper we have highlighted that there is value for a potential exporter to wait and identified the importance of factors such as entrepreneurial ability, learning, innovation and productivity growth, access to finance and random market events in triggering or stalling firm-level exporting.

\section{References}

[1] Bernard, A. B., Jensen J.B., Redding, S. and Schott, P.K. (2007). 'Firms in international trade', Journal of Economic Perspectives, 21, 105-130.

[2] Bernard, A.B. and Jensen, J.B. (1999). 'Exceptional exporter performance: Cause, effect, or both?', Journal of International Economics, 47, 1-25.

[3] Bernard, A.B., and Jensen, J.B. (2004). 'Why some firms export', Review of Economics and Statistics, 86, 561-569. 
[4] Castellani, D. and Giovannetti, G. (2010). 'Productivity and the international firm: dissecting h eterogeneity', Journal of Economic Policy Reform, 13 (1): $25-42$.

[5] Ceccagnoli, M. (2005). 'Firm Heterogeneity, Imitation, and the Incentives for Cost Reducing R\&D Effort', The Journal of Industrial Economics, 53 (1): $83-100$.

[6] Chang, H-H. and Van Marrewijk, C. (2011). 'Firm Heterogeneity and Development: Evidence from Latin American Countries', Discussion Paper Series 11-14, Tjalling C. Koopmans Institute, Utrecht School of Economics.

[7] Clerides,S. Lach,S. and Tybout, J. (1998). 'Is Learning by Exporting Important? Micro-dynamic Evidence from Columbia, Mexico and Morocco', Quarterly Journal of Economics, 113: 903-947.

[8] Costantini, J.A. and Melitz, M.J. (2008). 'The Dynamics of Firm-Level Adjustment to Trade'(In in Helpman, E., Marin, D. and Verdier, T. eds. The Organization of Firms in a Global Economy, Cambridge, MA: Harvard University Press)

[9] Dixit A. and Pindyck, R. (1994). Investment under Uncertainty. Princeton: Princeton University Press

[10] Dixit, A. (1989). 'Entry and Exit Decisions under Uncertainty', Journal of Political Economy, 97 (3): 620-638.

[11] Greenaway, D. and Kneller, R. (2007). 'Firm heterogeneity, exporting and foreign direct investment', Economic Journal, 117: F134-F161.

[12] Gilroy, B.M., and Lucas, E. (2006), The Choice between Greenfield Investment and Cross-border Acquisition: A Real Option Approach, The Quarterly Review of Economics and Finance, 46 (3): 447-465.

[13] Helpman, E., Melitz,M.J. and Yeaple, S.R. (2004). 'Export versus FDI with heterogeneous firms', American Economic Review, 94: 300-316.

[14] Johanson J. and Vahlne J-E. (1977). 'The Internationalization process of the firm - a model of knowledge development and increasing foreign market commitments', Journal of International Business Studies, 8(1): 23-31

[15] Marin, D. and Verdier, T. (2007). 'Competing in Organizations: Firm Heterogeneity and International Trade', GESY Discussion Paper no. $20 \%$.

[16] Melitz, M.J. (2003). 'The impact of trade on intra-industry reallocations and aggregate industry productivity', Econometrica, 71: 1695-1725.

[17] Naudé, W.A. and Rossouw, A. (2010). 'Early international entrepreneurship in China: Extent and determinants', Journal of International Entrepreneurship, 8 (1): 87-111. 
[18] Wagner, J. (2007). 'Exports and productivity: A survey of the evidence from firm-level data', The World Economy, 30: 60-82.

[19] Erdal Yalcin, (2009), "Uncertain Productivity Growth and the Choice between FDI and Export", CESifo Working Paper No. 2773, August 2009

\section{Appendices}

\subsection{Appendix 1: Proof of Proposition 1 and Derivatives of $\lambda$}

This is an extended appendix to make it easy for a referee to check all methods and calcualtions in detail. For a publication we would reduce the appendix to no more than 6 pages.

a) The value of the revenue stream is determined by

$$
\begin{aligned}
V_{i}^{\text {gross }} & =E \int_{T}^{\infty} e^{-r(t-T)} P_{i} d t \\
& =\int_{T}^{\infty} P_{i} e^{-r(t-T)} e^{\alpha_{i}(t-T)} \\
& =\left[\frac{1}{\alpha_{i}-r} e^{\left(\alpha_{i}-r\right)(t-T)} P_{i}\right]_{T}^{\infty} \\
& =\frac{P_{i}}{r-\alpha_{i}}
\end{aligned}
$$

b) For the option values $F_{i}$ the Hamilton-Jacobi-Bellman equation for the Brownian motion of 2 holds:

$$
r F=\frac{1}{d t} E(d F)
$$

From Ito's Lemma we know:

$$
\begin{aligned}
d F_{i} & =\left(\frac{\partial F_{i}}{\partial t}+\delta_{i} \tilde{P}_{i} \frac{\partial F_{i}}{\partial \tilde{P}_{i}}+\frac{1}{2} \sigma_{i}^{2} \tilde{P}_{i}^{2} \frac{\partial F_{i}}{\partial \tilde{P}_{i}^{2}}\right) d t+\sigma \tilde{P}_{i} \frac{\partial F_{i}}{\partial \tilde{P}_{i}} d W \\
& \Rightarrow E\left(d F_{i}\right)=\left(\frac{\partial F_{i}}{\partial t}+\delta_{i} \tilde{P}_{i} \frac{\partial F_{i}}{\partial \tilde{P}_{i}}+\frac{1}{2} \sigma_{i}^{2} \tilde{P}_{i}^{2} \frac{\partial F_{i}}{\partial \tilde{P}_{i}^{2}}\right) d t
\end{aligned}
$$

because $E(d W)=0$.

From the last two equations we obtain the following differential equation: 


$$
\begin{gathered}
\underbrace{\frac{\partial F_{i}}{\partial t}}_{=0}+\delta_{i} \tilde{P}_{i} \frac{\partial F_{i}}{\partial \tilde{P}_{i}}+\frac{1}{2} \sigma_{i}^{2} \tilde{P}_{i}^{2} \frac{\partial F_{i}}{\partial \tilde{P}_{i}^{2}}-r F_{i}=0 \\
\Leftrightarrow \delta_{i} \tilde{P}_{i} \frac{\partial F_{i}}{\partial \tilde{P}_{i}}+\frac{1}{2} \sigma_{i}^{2} \tilde{P}_{i}^{2} \frac{\partial F_{i}}{\partial \tilde{P}_{i}^{2}}-r F_{i}=0
\end{gathered}
$$

This is a second-order homogenous ordinary differential equation with a free boundary.

c) A general solution to this differential equation will be

$$
F=\tilde{P}^{\lambda} .
$$

$\sim \lambda$

$B P$ solves the homogenous differential equation.

$$
\begin{aligned}
\delta_{i} \tilde{P}_{i} B \lambda \tilde{P}_{i}^{\lambda-1}+\frac{1}{2} \sigma_{i}^{2} B \tilde{P}_{i}^{2} \lambda(\lambda-1) \tilde{P}_{i}^{\lambda-2}-r B \tilde{P}_{i}^{\lambda} & =0 \\
\delta_{i} B \lambda \tilde{P}_{i}^{\lambda}+\frac{1}{2} \sigma_{i}^{2} B \lambda(\lambda-1) \tilde{P}_{i}^{\lambda}-r B \tilde{P}_{i}^{\lambda} & =0 \\
\delta_{i} \lambda+\frac{1}{2} \sigma_{i}^{2} \lambda(\lambda-1)-r & =0 \\
\Leftrightarrow \lambda=\frac{1}{2}-\frac{\delta_{i}}{\sigma_{i}^{2}}+\sqrt{\left(\frac{1}{2}-\frac{\delta_{i}}{\sigma_{i}^{2}}\right)^{2}+\frac{2 r}{\sigma_{i}^{2}}}>1 & \text { see (11) }
\end{aligned}
$$

with $\delta_{i}<r \quad$ see $(12)$

As $\tilde{P}_{i}$ goes to zero, $F_{i}$ tends to approach 0 . This implies that the negative root of the characteristic polynomial should have no influence on $F_{i}$ as $\tilde{P}_{i}$ tends to zero.

Besides $\lambda>1 \Leftrightarrow r>\delta_{i}$ :

$$
\begin{aligned}
\frac{1}{2}-\frac{\delta_{i}}{\sigma_{i}^{2}}+\sqrt{\left(\frac{1}{2}-\frac{\delta_{i}}{\sigma_{i}^{2}}\right)^{2}+\frac{2 r}{\sigma_{i}^{2}}} & >1 \\
\sqrt{\left(\frac{1}{2}-\frac{\delta}{\sigma_{i}^{2}}\right)^{2}+\frac{2 r}{\sigma_{i}^{2}}} & >\frac{1}{2}+\frac{\delta_{i}}{\sigma_{i}^{2}} \\
\left(\frac{1}{2}-\frac{\delta_{i}}{\sigma_{i}^{2}}\right)^{2}+\frac{2 r}{\sigma_{i}^{2}} & >\left(\frac{1}{2}+\frac{\delta_{i}}{\sigma_{i}^{2}}\right)^{2} \\
-2 \frac{\delta_{i}}{\sigma_{i}^{2}} \frac{1}{2}+\frac{2 r}{\sigma_{i}^{2}} & >2 \frac{\delta_{i}}{\sigma_{i}^{2}} \frac{1}{2} \\
-\frac{\delta_{i}}{\sigma_{i}^{2}}+\frac{2 r}{\sigma_{i}^{2}} & >\frac{\delta_{i}}{\sigma_{i}^{2}} \\
r & >\delta_{i}
\end{aligned}
$$


For the derivatives of $\lambda$ we get:

$$
\begin{aligned}
& \frac{d \lambda}{d \delta}=-\frac{1}{\sigma^{2}}-\frac{2}{2}\left[\left(\frac{1}{2}-\frac{\delta}{\sigma^{2}}\right)^{2}+\frac{2 r}{\sigma^{2}}\right]^{\frac{1}{2}-1}\left(\frac{1}{2}-\frac{\delta}{\sigma^{2}}\right) \frac{1}{\sigma^{2}} \\
& =-\frac{1}{\sigma^{2}}\left[1+\left[\left(\frac{1}{2}-\frac{\delta}{\sigma^{2}}\right)^{2}+\frac{2 r}{\sigma^{2}}\right]^{-\frac{1}{2}}\left(\frac{1}{2}-\frac{\delta}{\sigma^{2}}\right)\right]<0 \\
& =-\frac{\left[\left(\frac{1}{2}-\frac{\delta}{\sigma^{2}}\right)^{2}+\frac{2 r}{\sigma^{2}}\right]^{-\frac{1}{2}}}{\sigma^{2}}\left[\left[\left(\frac{1}{2}-\frac{\delta}{\sigma^{2}}\right)^{2}+\frac{2 r}{\sigma^{2}}\right]^{\frac{1}{2}}+\left(\frac{1}{2}-\frac{\delta}{\sigma^{2}}\right)\right]<0 \\
& =-\frac{\left[\left(\frac{1}{2}-\frac{\delta}{\sigma^{2}}\right)^{2}+\frac{2 r}{\sigma^{2}}\right]^{-\frac{1}{2}}}{\sigma^{2}} \lambda<0 \\
& \frac{d \lambda}{d r}=\left[\left(\frac{1}{2}-\frac{\delta}{\sigma^{2}}\right)^{2}+\frac{2 r}{\sigma^{2}}\right]^{-\frac{1}{2}} \frac{1}{\sigma^{2}}>0 \\
& \frac{d \lambda}{d \sigma_{i}}=\frac{2 \delta_{i}}{\sigma_{i}^{3}}+\frac{1}{2}\left[\left(\frac{1}{2}-\frac{\delta_{i}}{\sigma_{i}^{2}}\right)^{2}+\frac{2 r}{\sigma_{i}^{2}}\right]^{-\frac{1}{2}}\left(2\left(\frac{1}{2}-\frac{\delta_{i}}{\sigma_{i}^{2}}\right) \cdot \frac{2 \delta_{i}}{\sigma_{i}^{3}}-\frac{4 r}{\sigma_{i}^{3}}\right) \\
& =\frac{2 \delta_{i}}{\sigma_{i}^{3}}+\left[\left(\frac{1}{2}-\frac{\delta_{i}}{\sigma^{2}}\right)^{2}+\frac{2 r}{\sigma_{i}^{2}}\right]^{-\frac{1}{2}}\left(\left(\frac{1}{2}-\frac{\delta_{i}}{\sigma_{i}^{2}}\right) \cdot \frac{2 \delta_{i}}{\sigma_{i}^{3}}-\frac{2 r}{\sigma_{i}^{3}}\right) \\
& =\frac{2 \delta_{i}}{\sigma_{i}^{3}}\left[1+\left[\left(\frac{1}{2}-\frac{\delta_{i}}{\sigma_{i}^{2}}\right)^{2}+\frac{2 r}{\sigma_{i}^{2}}\right]^{-\frac{1}{2}}\left(\left(\frac{1}{2}-\frac{\delta_{i}}{\sigma_{i}^{2}}\right)-\frac{r}{\delta_{i}}\right)\right] \\
& =\frac{2 \delta_{i}\left[\left(\frac{1}{2}-\frac{\delta_{i}}{\sigma_{i}^{2}}\right)^{2}+\frac{2 r}{\sigma_{i}^{2}}\right]^{-\frac{1}{2}}}{\sigma_{i}^{3}}\left[\left[\left(\frac{1}{2}-\frac{\delta_{i}}{\sigma_{i}^{2}}\right)^{2}+\frac{2 r}{\sigma_{i}^{2}}\right]^{\frac{1}{2}}+\frac{1}{2}-\frac{\delta_{i}}{\sigma_{i}^{2}}-\frac{r}{\delta_{i}}\right]<0
\end{aligned}
$$

d) At the investment trigger point $P_{i}^{*}$ the value of the option must equal the net value obtained by exercising it (value of the active project minus sunk cost of the investment). Hence the following must hold: 


$$
\begin{aligned}
F\left(P_{i}^{*}\right)= & V^{\text {gross }}\left(P_{i}^{*}\right)-I_{i}(T) . \\
= & \int_{T}^{\infty} P_{i}^{*} e^{-r(t-T)} e^{\alpha_{i}(t-T)}-\left[\int_{0}^{T} e^{r(T-t)} C_{i} d t+\bar{C}_{i}\right] \\
= & {\left[\frac{1}{\alpha_{i}-r} e^{\left(\alpha_{i}-r\right)(t-T)} P_{i}^{*}\right]_{T}^{\infty}-\left[\left[-\frac{C_{i}}{r} e^{r(T-t)}\right]_{0}^{T}+\bar{C}_{i}\right] } \\
= & 0-\frac{P_{i}^{*}}{\alpha_{i}-r} e^{\left(\alpha_{i}-r\right)(T-T)}-\left(-\frac{C_{i}}{r}+\frac{C_{i}}{r} e^{r T}+\bar{C}_{i}\right) \\
= & \frac{P_{i}^{*}}{r-\alpha_{i}}-\frac{C_{i}}{r}\left(e^{r T}-1\right)-\bar{C}_{i} \\
& B\left(P_{i}^{*}\right)^{\lambda}=\frac{P_{i}^{*}}{r-\alpha_{i}}-\frac{C_{i}}{r}\left(e^{r T}-1\right)-\bar{C}_{i}
\end{aligned}
$$

Besides for $I_{i}(T)>0$ we have to assume that $\bar{C}_{i}>\frac{C_{i}}{r}$.

The smooth-pasting condition requires that the two value functions meet tangentially:

$$
\begin{aligned}
\left(F\left(P_{i}^{*}\right)\right)^{\prime} & =\left(V^{\text {gross }}\left(P_{i}^{*}\right)\right)^{\prime} \\
& \Leftrightarrow B \lambda\left(P_{i}^{*}\right)^{\lambda-1}=\frac{1}{r-\alpha_{i}}
\end{aligned}
$$

This implies

$$
B\left(P_{i}^{*}\right)^{\lambda}=\frac{P_{i}^{*}}{\left(r-\alpha_{i}\right) \lambda}
$$

Now we compute the threshold $P_{i}^{*}$ :

$$
\begin{gathered}
\frac{P_{i}^{*}}{r-\alpha_{i}}-\frac{C_{i}}{r}\left(e^{r T}-1\right)-\bar{C}_{i}=\frac{P_{i}^{*}}{\left(r-\alpha_{i}\right) \lambda} \\
\Leftrightarrow \frac{P_{i}^{*} \lambda-P_{i}^{*}}{\left(r-\alpha_{i}\right) \lambda}=\frac{C_{i}}{r}\left(e^{r T}-1\right)+\bar{C}_{i} \\
\Leftrightarrow P_{i}^{*}(\lambda-1)=\left(r-\alpha_{i}\right) \lambda\left[\frac{C_{i}}{r}\left(e^{r T}-1\right)+\bar{C}_{i}\right] \\
\Leftrightarrow P_{i}^{*}(T)=\frac{\lambda}{\lambda-1}\left(r-\alpha_{i}\right)\left[\frac{C_{i}}{r}\left(e^{r T}-1\right)+\bar{C}_{i}\right]=\frac{\lambda}{\lambda-1}\left(r-\alpha_{i}\right) I_{i}(T)
\end{gathered}
$$

e) With $\ln I_{i}(T)$ being convex and hence $\ln P_{i}^{*}(T)$ being a convex function in $T$ :

$$
\frac{\partial \ln I_{i}}{\partial T}=\frac{C_{i} e^{r T}}{\frac{C_{i}}{r}\left(e^{r T}-1\right)+\bar{C}_{i}}>0,
$$




$$
\begin{aligned}
& \frac{\partial^{2} \ln I_{i}}{\partial T^{2}}=\frac{C_{i} r e^{r T}\left(\frac{C_{i}}{r}\left(e^{r T}-1\right)+\bar{C}_{i}\right)-C_{i}^{2} e^{2 r T}}{\left(\frac{C_{i}}{r}\left(e^{r T}-1\right)+\bar{C}_{i}\right)^{2}}>0 \\
& =\frac{\left.C_{i} r e^{r T} \frac{C_{i}}{r} e^{r T}-\frac{C_{i}}{r} C_{i} r e^{r T}+C_{i} r e^{r T} \bar{C}_{i}\right)-C_{i}^{2} e^{2 r T}}{\left(\frac{C_{i}}{r}\left(e^{r T}-1\right)+\bar{C}_{i}\right)^{2}} \\
& =\frac{-\frac{C_{i}}{r} C_{i} r e^{r T}+C_{i} r e^{r T} \bar{C}_{i}}{\left(\frac{C_{i}}{r}\left(e^{r T}-1\right)+\bar{C}_{i}\right)^{2}} \\
& =\frac{C_{i} e^{r T}\left(r \bar{C}_{i}-C_{i}\right)}{\left(\frac{C_{i}}{r}\left(e^{r T}-1\right)+\bar{C}_{i}\right)^{2}}>0(\text { convex }) \text { as we assume condition } \\
& \lim _{T \rightarrow \infty} \frac{\partial \ln I_{i}}{\partial T}=\lim _{T \rightarrow \infty} \frac{C_{i} e^{r T}}{\frac{C_{i}}{r}\left(e^{r T}-1\right)+\bar{C}_{i}}=\lim _{T \rightarrow \infty} \frac{r e^{r T}}{\left[e^{r T}-1+\frac{r \bar{C}_{i}}{C_{i}}\right]} \\
& =\lim _{T \rightarrow \infty} \frac{r e^{r T}}{\left[1+\frac{-1+\frac{r \bar{C}_{i}}{C_{i}}}{e^{r T}}\right] e^{r T}}=r
\end{aligned}
$$

\subsection{Appendix 2: Deriving $\mathrm{T}$ and Proof of Proposition 2}

a) Development of the pre-start-up (initial) market value: Expected Path of pre-start-up (initial) market values: The development of the pre-startup market value is determined by

$$
d \tilde{P}_{i}=\delta_{i} \tilde{P}_{i}+\sigma_{i} \tilde{P}_{i} d W
$$

We put $g(x)=\log x$ to get the Ito formula for $\log \tilde{P}_{i}(t)$ :

$$
\begin{aligned}
d\left(\log \tilde{P}_{i}(t)\right) & =\left(\frac{1}{\tilde{P}_{i}(t)} \delta_{i} \tilde{P}_{i}(t)+\frac{1}{2}\left(-\frac{1}{\tilde{P}_{i}(t)^{2}}\right) \tilde{P}_{i}{ }^{2} \sigma_{i}^{2}\right) d t+\frac{1}{\tilde{P}_{i}(t)} \sigma_{i} \tilde{P}_{i}(t) d W \\
& =\left(\delta_{i}-\frac{1}{2} \sigma_{i}^{2}\right) d t+\sigma_{i} d W
\end{aligned}
$$

We obtain after integration

$$
\begin{aligned}
\log \tilde{P}_{i}(T)-\log \tilde{P}_{i}(0) & =\int_{0}^{T}\left(\delta_{i}-\frac{1}{2} \sigma_{i}^{2}\right) d t+\int_{0}^{T} \sigma_{i} d W \\
& \Leftrightarrow \log \tilde{P}_{i}(T)=\log \tilde{P}_{i}(0)+\left(\delta_{i}-\frac{1}{2} \sigma_{i}^{2}\right) T+\sigma_{i} W(T), \text { and hence } \\
\tilde{P}_{i}(T)= & \tilde{P}_{i}(0) e^{\left(\left(\delta_{i}-\frac{1}{2} \sigma_{i}^{2}\right) T+\sigma_{i} W(T)\right)} \quad \text { and hence } \\
E \tilde{P}_{i}(T)= & \tilde{P}_{i}(0) e^{\delta_{i} T} . \\
& \frac{\partial E \tilde{P}_{i}(T)}{\partial T}=\delta_{i} \tilde{P}_{i}(0) e^{\delta_{i} T}
\end{aligned}
$$


and $\ln E \tilde{P}_{i}(T)$ is a linear function in $T$ :

$$
\ln E \tilde{P}_{i}(T)=\ln \tilde{P}_{i}(0)+\delta_{i} T
$$

Expected First-Time Realization of pre-start-up (initial) market values: We can determine the expected time $E\left(\tilde{T}_{i}\right)$ time needed to reach a certain pre-startup (initial) market value $\tilde{P}_{i, x}$ for the first time given the present value $\tilde{P}_{i}(0)$. By using the Girsanov theorem we can derive the probability density function of $\tilde{T}_{i}{ }^{5}$ given by

$$
f\left(\tilde{T}_{i}, \tilde{P}(0), \tilde{P}_{i}\right)=\frac{\ln \left(\frac{\tilde{P}_{i, x}}{\tilde{P}_{i}(0)}\right)}{\sqrt{2 \pi \sigma_{i}^{2}\left(\tilde{T}_{i}\right)^{3}}} e^{-\frac{\left(\ln \left(\frac{\tilde{P}_{i, x}}{P_{i}(0)}\right)-\left(\alpha_{i}-\frac{1}{2} \sigma_{i}^{2}\right) \tilde{T}_{i}\right)^{2}}{2 \sigma_{i}^{2} \tilde{T}_{i}}}
$$

with $\tilde{P}_{i, x}>\tilde{P}_{i}(0)$. With the Laplace transformation of $T^{6}$ :

$$
\begin{aligned}
E\left(e^{-\lambda \tilde{T}_{i}}\right) & =\int_{0}^{\infty} e^{-\lambda \tilde{T}_{i}} f\left(\tilde{T}_{i}\right) d \tilde{T}_{i} \\
& =e^{-\left[\sqrt{\left(\alpha_{i}-\frac{1}{2} \sigma_{i}^{2}\right)^{2}+2 \sigma_{i}^{2} \lambda}-\left(\alpha_{i}-\frac{1}{2} \sigma_{i}^{2}\right)\right] \frac{\ln \left(\frac{\tilde{P}_{i, x}}{\tilde{P}_{i}(0)}\right)}{\sigma_{i}^{2}}}
\end{aligned}
$$

we determine the expected time before market entry as

$$
\begin{aligned}
E\left(\tilde{T}_{i, x}\right) & =\int_{0}^{\infty} \tilde{T}_{i} f\left(\tilde{T}_{i}\right) d T \\
& =\frac{\ln \left(\frac{\tilde{P}_{i, x}}{\tilde{P}_{i, 0}}\right)}{\delta_{i}-\frac{1}{2} \sigma_{i}^{2}}
\end{aligned}
$$

For each $\tilde{P}_{i, x}$ we can determine each expected time $E\left(\tilde{T}_{i, x}\right)$ when this initial income level $\tilde{P}_{i, x}$ is reached for the first time. Hence for a continuous variation of $\tilde{P}_{i, x}>\tilde{P}_{i}(0), \tilde{P}_{i, x} \in \mathbb{R}$ we can write $E\left(\tilde{T}_{i}\right)$ as a function of any potential initial income level $\tilde{P}_{i}$

$$
E\left(\tilde{T}_{i}\right)=\frac{\ln \left(\frac{\tilde{P}_{i}}{\tilde{P}_{i, 0}}\right)}{\delta-\frac{1}{2} \sigma^{2}} . \quad \text { see }(13) .
$$

Later we want to discuss the existence of the expected time $T^{*}$ of market entry for the threshold $P_{i}^{*}(T)$ (first passage time for the threshold $P_{i}^{*}$ (see 10)). Therefore, , for each existing $E \tilde{T}=T$ we rewrite (13) as a conituous function $f$ of time $T$

$$
\tilde{P}_{i}=\tilde{P}_{i, 0} e^{T\left(\delta_{i}-\frac{1}{2} \sigma_{i}^{2}\right)}=: f(T) .
$$

\footnotetext{
${ }^{5}$ An extensive discussion is offered by Karatzas and Shreve (1991, p.196) or by Karlin and Taylor (1975, p.363).

${ }^{6}$ See Ross (1996) Proposition 8.4.1.
} 
(a)

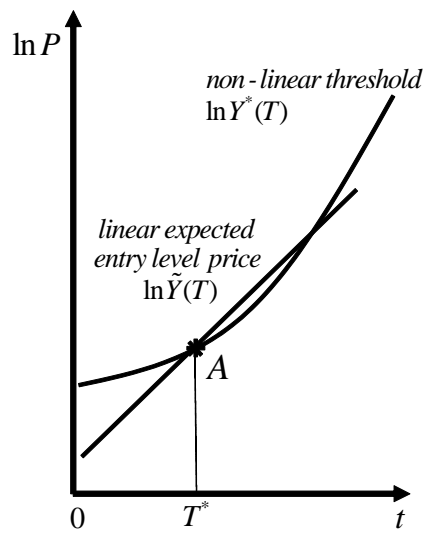

(b)

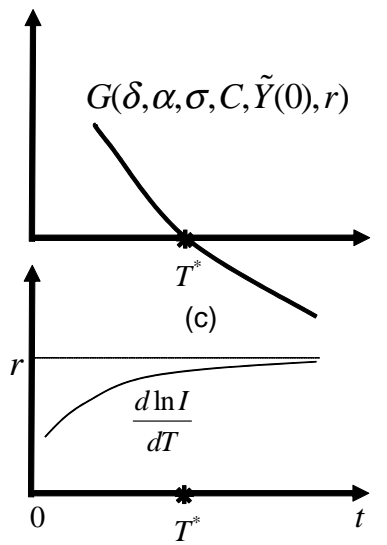

$\ln f(T)$ is a linear function in $T$ :

$$
\ln f(T)=\ln \tilde{P}_{i, 0}+T\left(\delta_{i}-\frac{1}{2} \sigma_{i}^{2}\right) .
$$

\subsection{Appendix 3: Existence of a solution for the expected time $T^{*}$ of market entry, and determination of $T^{*}$ as an implicit function/Proof of Proposition 3:}

In general we look for conditions described in figure 5.3. The threshold starts above the pres-start-up (initial) market value curve. For positive $T$ the threshold will have an unique intersection with the initial value curve from below at $A$. Hence at the time of expected market entry denoted by $T^{*} G=P_{i}^{*}(T)-f(T)=$ 0 and the $G$-curve has a negative slope $\frac{d G}{d T}<0$.

Further, at $T^{*}$ the threshold $P_{i}^{*}(T=0)$ must start above $f(E(T))$, and $G>0$ during the pre-market entry period $\left(0<t<T^{*}\right)$. Otherwise the market entry would have been taken place. 


\subsubsection{Negative slope of $G$}

$$
\begin{aligned}
& \frac{\partial G}{\partial T^{*}}=\frac{\lambda}{\lambda-1}\left(r-\alpha_{i}\right) C_{i} e^{r T^{*}}-\left(\delta_{i}-\frac{1}{2} \sigma_{i}^{2}\right) \tilde{P}_{i}(0) e^{\left(\delta_{i}-\frac{1}{2} \sigma_{i}^{2}\right) T^{*}}<0 \\
& \Leftrightarrow \quad \tilde{P}_{i}(0)>\frac{\lambda}{\lambda-1} \frac{\left(r-\alpha_{i}\right)}{\left(\delta_{i}-\frac{1}{2} \sigma_{i}^{2}\right)} C_{i} e^{\left(r-\left(\delta_{i}-\frac{1}{2} \sigma_{i}^{2}\right)\right) T^{*}} \\
& \Leftrightarrow \frac{\lambda}{\lambda-1}\left(r-\alpha_{i}\right)\left[\frac{C_{i}}{r} e^{\left(r-\left(\delta_{i}-\frac{1}{2} \sigma_{i}^{2}\right)\right) T^{*}}-\left(\frac{C_{i}}{r}-\bar{C}_{i}\right) e^{-\left(\delta_{i}-\frac{1}{2} \sigma_{i}^{2}\right) T^{*}}\right] \\
& >\frac{\lambda}{\lambda-1} \frac{\left(r-\alpha_{i}\right)}{\left(\delta_{i}-\frac{1}{2} \sigma_{i}^{2}\right)} C_{i} e^{\left(r-\left(\delta_{i}-\frac{1}{2} \sigma_{i}^{2}\right)\right) T^{*}} \\
& \Leftrightarrow \frac{C_{i}}{r} e^{\left(r-\left(\delta_{i}-\frac{1}{2} \sigma_{i}^{2}\right)\right) T^{*}}-\left(\frac{C_{i}}{r}-\bar{C}_{i}\right) e^{-\left(\delta_{i}-\frac{1}{2} \sigma_{i}^{2}\right) T^{*}}>\frac{C_{i}}{\left(\delta_{i}-\frac{1}{2} \sigma_{i}^{2}\right)} e^{\left(r-\left(\delta_{i}-\frac{1}{2} \sigma_{i}^{2}\right)\right) T^{*}} \\
& \Leftrightarrow \frac{C_{i}}{r}+\left(-\frac{C_{i}}{r}+\bar{C}_{i}\right) e^{-r T^{*}}>\frac{C_{i}}{\left(\delta_{i}-\frac{1}{2} \sigma_{i}^{2}\right)} \\
& \Leftrightarrow \quad\left(-\frac{C_{i}}{r}+\bar{C}_{i}\right) e^{-r T^{*}}>\frac{C_{i}}{\left(\delta_{i}-\frac{1}{2} \sigma_{i}^{2}\right)}-\frac{C_{i}}{r} \\
& \Leftrightarrow \quad e^{-r T^{*}}>\frac{\frac{C_{i}}{\left(\delta_{i}-\frac{1}{2} \sigma_{i}^{2}\right)}-\frac{C_{i}}{r}}{-\frac{C_{i}}{r}+\bar{C}_{i}} \\
& \Leftrightarrow \quad-r T^{*}>\ln \left(\frac{\frac{C_{i}}{\left(\delta_{i}-\frac{1}{2} \sigma_{i}^{2}\right)}-\frac{C_{i}}{r}}{-\frac{C_{i}}{r}+\bar{C}_{i}}\right) \Leftrightarrow T^{*}<\frac{-1}{r} \ln \left(\frac{\frac{C_{i}}{\left(\delta-\frac{1}{2} \sigma^{2}\right)}-\frac{C_{i}}{r}}{-\frac{C_{i}}{r}+\bar{C}_{i}}\right) \\
& \Leftrightarrow \frac{C_{i}}{\left(\delta_{i}-\frac{1}{2} \sigma_{i}^{2}\right)}<\bar{C}_{i} \Leftrightarrow C_{i}<\left(\delta_{i}-\frac{1}{2} \sigma_{i}^{2}\right) \bar{C}_{i}<r \bar{C}_{i} \quad \text { see } \quad 16
\end{aligned}
$$

Before market entry the initial income curve must grow faster than the threshold curve. Only for a negative slope $G$ can approach and eventually reach zero. $\frac{\partial G}{\partial T}<0$ is fulfilled if condition $\bar{C}_{i}>\frac{C_{i}}{r}$ (condition 16)

\subsubsection{Existence of an intersect of $P_{i}^{*}\left(T^{*}\right)$ and $f\left(E\left(T^{*}\right)\right)$ for positive $T^{*}$}

a) As the function $\ln P_{i}^{*}(T)$ is convex if condition (16) holds (see 21) and the function $\ln f(T)$ is linear, there are at most two intersections. We are interested only in intersections at $T>0$. An intersection for positive values of both functions exsits if condition (15) and (16) holds and $G=0$ for positive values of $T^{*}$. 


$$
\begin{aligned}
& G= P_{i}^{*}\left(T^{*}\right)-f\left(T^{*}\right)=0 \\
&= \frac{\lambda}{\lambda-1}\left(r-\alpha_{i}\right)\left[\frac{C_{i}}{r}\left(e^{r T^{*}}-1\right)+\bar{C}_{i}\right]-\tilde{P}_{i}(0) e^{\left(\delta_{i}-\frac{1}{2} \sigma_{i}^{2}\right) T^{*}}=0 \\
& \Leftrightarrow \ln \left[\frac{\lambda}{\lambda-1}\left(r-\alpha_{i}\right)\left[\frac{C_{i}}{r}\left(e^{r T^{*}}-1\right)+\bar{C}_{i}\right]\right]=\ln \tilde{P}_{i}(0)+\left(\delta_{i}-\frac{1}{2} \sigma_{i}^{2}\right) T^{*} \\
& \Leftrightarrow \ln \left[\frac{\lambda}{\lambda-1}\left(r-\alpha_{i}\right)\left[\frac{C_{i}}{r}\left(e^{r T^{*}}-1\right)+\bar{C}_{i}\right]\right]-\ln \tilde{P}_{i}(0)=\left(\delta_{i}-\frac{1}{2} \sigma_{i}^{2}\right) T^{*} \\
& \Leftrightarrow \frac{1}{\left(\delta_{i}-\frac{1}{2} \sigma_{i}^{2}\right)} \ln \left[\frac{\frac{\lambda}{\lambda-1}\left(r-\alpha_{i}\right)\left[\frac{C_{i}}{r}\left(e^{r T^{*}}-1\right)+\bar{C}_{i}\right]}{\tilde{P}_{i}(0)}\right]=T^{*} \stackrel{!}{>} 0 \\
& \Rightarrow \quad \frac{\lambda}{\lambda-1}\left(r-\alpha_{i}\right)\left[\frac{C_{i}}{r}\left(e^{r T^{*}}-1\right)+\bar{C}_{i}\right]>\tilde{P}_{i}(0) \\
& \Leftrightarrow \quad \frac{\lambda}{\lambda-1}\left(r-\alpha_{i}\right) \frac{C_{i}}{r} e^{r T^{*}}>\tilde{P}_{i}(0)+\frac{\lambda}{\lambda-1}\left(r-\alpha_{i}\right)\left(\frac{C_{i}}{r}-\bar{C}_{i}\right) \\
& \Leftrightarrow \quad e^{r T^{*}}>\frac{\lambda-1}{\lambda} \frac{1}{\left(r-\alpha_{i}\right)} \frac{r}{C_{i}} \tilde{P}_{i}(0)+1-\bar{C}_{i} \frac{r}{C_{i}} \\
& \Leftrightarrow \quad T^{*}>\frac{1}{r} \ln [\underbrace{<\frac{r}{C_{i}} \bar{C}_{i}>\frac{\lambda-1}{\lambda} \frac{1}{\left(r-\alpha_{i}\right)} \frac{r}{C_{i}}}_{\frac{\lambda-1}{\lambda} \frac{1}{\left(r-\alpha_{i}\right)} \frac{r}{C_{i}} \tilde{P}_{i}(0)+1-\frac{r}{C_{i}} \bar{C}_{i}} \tilde{P}_{i}(0) \\
& \Leftrightarrow \bar{C}_{i}>\frac{\lambda-1}{\lambda} \frac{1}{\left(r-\alpha_{i}\right)} \tilde{P}_{i}(0)
\end{aligned}
$$

The last inequality is a condition for the axis intercepts of $P_{i}^{*}$ and $f(T)$. It guarantees that $f(T)$ has a lower value in $T=0$ than $P_{i}^{*}$.

$$
\begin{aligned}
P_{i}^{*}(0) & >f(E(0)) \\
& \Rightarrow \bar{C}>\frac{\lambda-1}{\lambda} \frac{1}{(r-\alpha)} \tilde{P}_{i}(0)
\end{aligned}
$$

b) Further, in figure 5.3 the condition for an intersection and a negative slope have to hold simultaneously at $T^{*}$. We need to show that there is a $T^{*}$ were both $\frac{d G}{d T}<0$ and $G=0$ hold. That is, we can find a minimum level for 
$\tilde{P}_{i}(0)$ in order to ensure an intersection and a negative slope:

$$
\begin{aligned}
& \underbrace{\frac{1}{\delta_{i}-\frac{1}{2} \sigma_{i}^{2}} \ln \left[\frac{\frac{\lambda}{\lambda-1}\left(r-\alpha_{i}\right)\left[\frac{C_{i}}{r}\left(e^{r T^{*}}-1\right)+\bar{C}_{i}\right]}{\tilde{P}_{i}(0)}\right]}_{\text {follows from } G=0}=T^{*}<\underbrace{\frac{-1}{r} \ln \left(\frac{\frac{C_{i}}{\delta_{i}-\frac{1}{2} \sigma_{i}^{2}}-\frac{C_{i}}{r}}{-\frac{C_{i}}{r}+\bar{C}_{i}}\right)}_{\text {follows from the slope condition }} \\
& \frac{1}{\delta_{i}-\frac{1}{2} \sigma_{i}^{2}} \ln \left[\frac{\lambda}{\lambda-1}\left(r-\alpha_{i}\right)\left[\frac{C_{i}}{r}\left(e^{r T^{*}}-1\right)+\bar{C}_{i}\right]\right]-\frac{1}{\delta_{i}-\frac{1}{2} \sigma_{i}^{2}} \ln \tilde{P}_{i}(0)<\frac{-1}{r} \ln \left(\frac{\frac{C_{i}}{\delta_{i}-\frac{1}{2} \sigma_{i}^{2}}-\frac{C_{i}}{r}}{-\frac{C_{i}}{r}+\bar{C}_{i}}\right) \\
& \ln \left[\frac{\lambda}{\lambda-1}\left(r-\alpha_{i}\right)\left[\frac{C_{i}}{r}\left(e^{r T^{*}}-1\right)+\bar{C}_{i}\right]\right]+\frac{\delta_{i}-\frac{1}{2} \sigma_{i}^{2}}{r} \ln \left(\frac{\frac{C_{i}}{\delta_{i}-\frac{1}{2} \sigma_{i}^{2}}-\frac{C_{i}}{r}}{-\frac{C_{i}}{r}+\bar{C}_{i}}\right)<\ln \tilde{P}_{i}(0) \\
& \ln \left[\frac{\lambda}{\lambda-1}\left(r-\alpha_{i}\right)\left[\frac{C_{i}}{r}\left(e^{r T^{*}}-1\right)+\bar{C}_{i}\right]\right]+\underbrace{\frac{\delta_{i}-\frac{1}{2} \sigma_{i}^{2}}{r} \ln \left(\frac{\frac{C_{i}}{\delta_{i}-\frac{1}{2} \sigma_{i}^{2}}-\frac{C_{i}}{r}}{-\frac{C_{i}}{r}+\bar{C}_{i}}\right)}_{c<0}<\ln \tilde{P}_{i}(0) \\
& {\left[\frac{\lambda}{\lambda-1}\left(r-\alpha_{i}\right)\left[\frac{C_{i}}{r}\left(e^{r T^{*}}-1\right)+\bar{C}_{i}\right]\right] e^{c}<\tilde{P}_{i}(0)} \\
& \frac{\lambda}{\lambda-1}\left(r-\alpha_{i}\right) \frac{C_{i}}{r} e^{r T^{*}} e^{c}-\frac{\lambda}{\lambda-1}\left(r-\alpha_{i}\right) \frac{C_{i}}{r} e^{c}+\frac{\lambda}{\lambda-1}\left(r-\alpha_{i}\right) \bar{C} e^{c}<\tilde{P}_{i}(0) \\
& \frac{\lambda}{\lambda-1}\left(r-\alpha_{i}\right) \frac{C_{i}}{r} e^{r T^{*}} e^{c}<\tilde{P}_{i}(0)+\frac{\lambda}{\lambda-1}\left(r-\alpha_{i}\right) \frac{C_{i}}{r} e^{c}-\frac{\lambda}{\lambda-1}\left(r-\alpha_{i}\right) \bar{C}_{i} e^{c} \\
& e^{r T^{*}} e^{c}<\tilde{P}_{i}(0) \frac{r}{C_{i}} \frac{1}{\left(r-\alpha_{i}\right)} \frac{\lambda-1}{\lambda}+e^{c}-\frac{r \bar{C}_{i}}{C_{i}} e^{c} \\
& e^{r T^{*}}<\tilde{P}_{i}(0) \frac{r}{C_{i}} \frac{1}{\left(r-\alpha_{i}\right)} \frac{\lambda-1}{\lambda} e^{-c}+1-\frac{r \bar{C}_{i}}{C_{i}} \\
& T^{*}<\frac{1}{r} \ln \left(\tilde{P}_{i}(0) \frac{r}{C_{i}} \frac{1}{\left(r-\alpha_{i}\right)} \frac{\lambda-1}{\lambda} e^{-c}+1-\frac{r \bar{C}_{i}}{C_{i}}\right) \\
& \tilde{P}_{i}(0) \frac{r}{C_{i}} \frac{1}{\left(r-\alpha_{i}\right)} \frac{\lambda-1}{\lambda} e^{-c}+1-\frac{r \bar{C}_{i}}{C_{i}}>1 \\
& \tilde{P}_{i}(0)>\bar{C}_{i} \frac{\lambda}{\lambda-1}\left(r-\alpha_{i}\right) e^{c}
\end{aligned}
$$

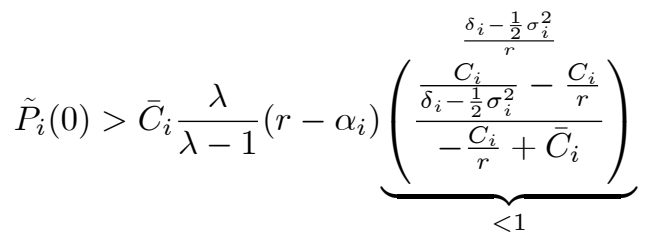


Finally, $\tilde{P}_{i}(0)$ has to lie in the open interval $\left(\bar{C}_{i} \frac{\lambda}{\lambda-1}\left(r-\alpha_{i}\right), \bar{C}_{i} \frac{\lambda}{\lambda-1}\left(r-\alpha_{i}\right)\left(\frac{\frac{C_{i}}{\delta_{i}-\frac{1}{2} \sigma_{i}^{2}}-\frac{C_{i}}{r}}{-\frac{C_{i}}{r}+\bar{C}_{i}}\right)^{\frac{\delta_{i}-\frac{1}{2} \sigma_{i}^{2}}{r}}\right)$.

\subsection{3 c) $T^{*}$ as implicit function of various variables: Proof of proposi- ton 3}

Proof of Proposition 3: (i) condition , (15) hold,

(ii) the derivative $\frac{\partial G}{\partial T}\left(\alpha_{i}, r_{i}, \sigma_{i}, T_{i}^{*}, C_{i}, \tilde{P}_{i}(0), \delta_{i}, \bar{C}_{i}\right)$ is negative (see condition (22)) for each vector $\left(\alpha_{i}, r, \sigma_{i}, T_{i}^{*}, C_{i}, \tilde{P}_{i}(0), \delta_{i}, \bar{C}_{i}\right)$ and

(iii) the partial derivatives of $G$ by of $\alpha_{i}, \sigma_{i}, C_{i}, \tilde{P}_{i}(0), \delta_{i}, \bar{C}_{i}$ and $r$ are continuous (vide infra), we can apply the implicit function theorem. Hence for a marginal environment of any vector $\left(\alpha_{i}, r, \sigma_{i}, T_{i}^{*}, C_{i}, \tilde{P}_{i}(0), \delta_{i}, \bar{C}_{i}\right), T_{i}^{*}$ is an implicit function of of $\alpha_{i}, \sigma_{i}, C_{i}, \tilde{P}_{i}(0), \delta_{i}, \bar{C}_{i}$ and $r$. q.e.d.

$$
T_{i}^{*}=T^{*}\left(\alpha_{i}, \sigma_{i}, C_{i}, \tilde{P}_{i}(0), \delta_{i}, r, \bar{C}_{i}\right)
$$

\subsection{4 d) Curve properties of $V_{i}=V_{i}^{\text {gross }}-I_{i} \quad$ (Net Current Value)}

$$
\begin{aligned}
V_{i} & =\frac{\tilde{P}_{i}(0) e^{\delta_{i} T}}{r-\alpha_{i}}-\frac{C_{i}}{r}\left(e^{r T}-1\right)-\bar{C}_{i} \\
& \Rightarrow \quad\left(V_{i}^{\text {gross }}-I_{i}\right)(0)=\frac{\tilde{P}_{i}(0)}{r-\alpha_{i}}-\bar{C}_{i} \\
& \frac{d(V)}{d T}=\frac{\delta_{i} \tilde{P}_{i}(0) e^{\delta_{i} T}}{r-\alpha_{i}}-C_{i} e^{r T}
\end{aligned}
$$

Maximum of the curve:

$$
\begin{aligned}
0 & =\frac{d(V)}{d T}=\frac{\delta_{i} \tilde{P}_{i}(0) e^{\delta_{i} T}}{r-\alpha_{i}}-C_{i} e^{r T} \Rightarrow \ln \left[\frac{\delta_{i} \tilde{P}_{i}(0)}{r-\alpha_{i}}\right]+\delta_{i} T=\ln C_{i}+r T \\
& \Leftrightarrow \quad T=\frac{1}{r-\delta_{i}} \ln \left[\frac{\tilde{P}_{i}(0)}{r-\alpha_{i}} \frac{\delta_{i}}{C_{i}}\right]
\end{aligned}
$$




$$
\begin{aligned}
\frac{d^{2}(V)}{d T^{2}} & =\frac{\delta^{2} \tilde{P}_{i}(0) e^{\delta T}}{r-\alpha_{i}}-r C_{i} e^{r T}<0 \\
& \Leftrightarrow r C_{i} e^{r T}>\frac{\delta_{i}^{2} \tilde{P}_{i}(0) e^{\delta_{i} T}}{r-\alpha_{i}} \\
& \Leftrightarrow \ln \left(r C_{i}\right)+r T>\ln \left(\frac{\delta_{i}^{2} \tilde{P}_{i}(0)}{r-\alpha_{i}}\right)+\delta_{i} T \\
& \Leftrightarrow T>\frac{1}{r-\delta_{i}} \ln \left(\frac{\delta_{i}^{2} \tilde{P}_{i}(0)}{r-\alpha_{i}} \frac{1}{r C_{i}}\right) \\
\text { for } T= & \frac{1}{r-\delta_{i}} \ln \left[\frac{\tilde{P}_{i}(0)}{r-\alpha_{i}} \frac{\delta}{C_{i}}\right] \text { we get } \\
\frac{\delta_{i}}{r}> & 1 \\
& \frac{\partial V}{\partial C}=-\frac{1}{r} e^{r T}<0
\end{aligned}
$$

\subsection{Appendix 4: Proof of Proposition 4}

To apply comparative statics for the implicit function $T_{i}^{*}=T_{i}^{*}\left(\alpha_{i}, \sigma_{i}, C_{i}, \tilde{P}_{i}(0), \delta_{i} r_{i}\right)$ we need to consider $i$

$$
\frac{\partial G}{\partial T}=\frac{\lambda}{\lambda-1}\left(r-\alpha_{i}\right) C_{i} e^{r T}-\left(\delta_{i}-\frac{1}{2} \sigma_{i}^{2}\right) \tilde{P}_{i}(0) e^{\left(\delta_{i}-\frac{1}{2} \sigma_{i}^{2}\right) T} \gtreqless 0
$$

Since we are only interested in values of $T^{*}$ described by point $A$ in figure 5.3 conditions (15) and $\frac{\partial G}{\partial T^{*}}<0(16)$. Then at $T^{*}$ we obtain:

$$
\begin{aligned}
& \frac{d T^{*}}{d \sigma}=-\frac{\frac{d G}{d \sigma}}{\frac{\partial G}{\partial T}}=-\frac{\left[\frac{-\frac{\partial \lambda}{\partial \sigma_{i}}}{(\lambda-1)^{2}}\left\{\left(r-\alpha_{i}\right) \frac{C_{i}}{r} e^{r T}-\left(r-\alpha_{i}\right) \frac{C_{i}}{r}+\bar{C}_{i}\left(r-\alpha_{i}\right)\right\}\right]}{\frac{\lambda}{\lambda-1}\left(r-\alpha_{i}\right) C_{i} e^{r T}-\left(\delta_{i}-\frac{1}{2} \sigma_{i}^{2}\right) \tilde{P}_{i}(0) e^{\left(\delta_{i}-\frac{1}{2} \sigma_{i}^{2}\right) T}}
\end{aligned}
$$

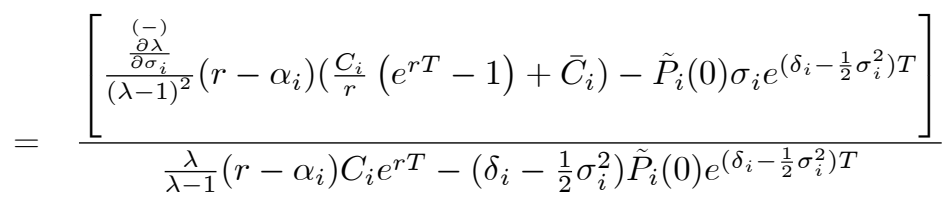

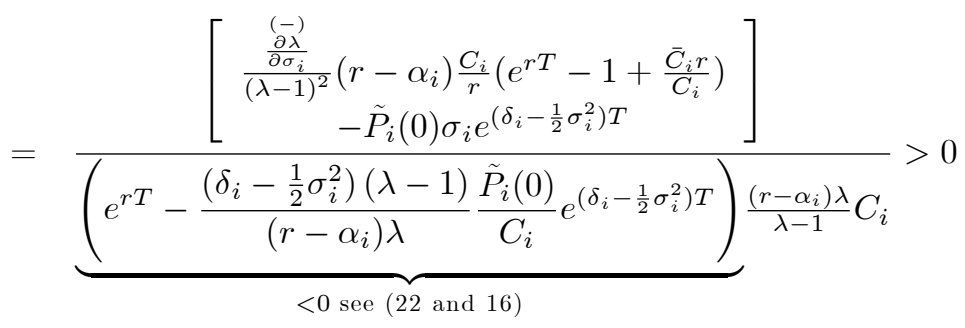




\subsection{Appendix 5: Proof of Proposition 5}

$$
\begin{aligned}
\frac{d T^{*}}{d \alpha} & =-\frac{\frac{d G}{d \alpha}}{\frac{\partial G}{\partial T}}=-\frac{\left[-\frac{\lambda}{\lambda-1} \frac{C_{i}}{r} e^{r T}+\frac{\lambda}{\lambda-1} \frac{C_{i}}{r}-\bar{C}_{i} \frac{\lambda}{\lambda-1}\right]}{\frac{\lambda}{\lambda-1}\left(r-\alpha_{i}\right) C_{i} e^{r T}-\left(\delta_{i}-\frac{1}{2} \sigma_{i}^{2}\right) \tilde{P}_{i}(0) e^{\left(\delta_{i}-\frac{1}{2} \sigma_{i}^{2}\right) T}} \\
& =\frac{1}{\left(e^{r T}-\frac{\left(\delta_{i}-\frac{1}{2} \sigma_{i}^{2}\right)(\lambda-1)}{(r-\alpha) \lambda} \frac{\tilde{P}_{i}(0)}{C_{i}} e^{\left(\delta_{i}-\frac{1}{2} \sigma_{i}^{2}\right) T}\right) \frac{\lambda\left(r-\alpha_{i}\right)}{\lambda-1} C_{i}} \frac{\lambda}{\lambda-1} \frac{C_{i}}{r}\left[e^{r T}-1+\frac{\bar{C}_{i} r}{C_{i}}\right]<0 \\
& =\frac{\left[e^{r T}-1+\frac{\bar{C}_{i} r}{C_{i}}\right]}{\underbrace{\left(e^{r T}-\frac{\left(\delta_{i}-\frac{1}{2} \sigma_{i}^{2}\right)(\lambda-1)}{\left(r-\alpha_{i}\right) \lambda} \frac{\tilde{P}_{i}(0)}{C_{i}} e^{\left(\delta_{i}-\frac{1}{2} \sigma_{i}^{2}\right) T}\right)}_{<0 \text { see }(22 \text { and } 16)} \frac{1}{\left(r-\alpha_{i}\right) r}<0}
\end{aligned}
$$

\subsection{Appendix 6: Proof of Proposition 6}

$$
\begin{aligned}
& \frac{d T^{*}}{d \tilde{P}_{i}(0)}=-\frac{\frac{d G}{d \tilde{P}_{i}(0)}}{\frac{\partial G}{\partial T}}=\frac{-1}{\frac{\lambda}{\lambda-1}\left(r-\alpha_{i}\right) C_{i} e^{r T}-\left(\delta_{i}-\frac{1}{2} \sigma_{i}^{2}\right) \tilde{P}_{i}(0) e^{\left(\delta_{i}-\frac{1}{2} \sigma_{i}^{2}\right) T}}\left[-e^{\left(\delta_{i}-\frac{1}{2} \sigma_{i}^{2}\right) T}\right] \\
& =\frac{1}{\underbrace{\frac{\lambda}{\lambda-1}\left(r-\alpha_{i}\right) C_{i} e^{\left(r-\left(\delta_{i}-\frac{1}{2} \sigma_{i}^{2}\right)\right) T}-\left(\delta_{i}-\frac{1}{2} \sigma_{i}^{2}\right) \tilde{P}_{i}(0)}_{<0 \text { see }(22 \text { and 16) }}}<0
\end{aligned}
$$

\subsection{Appendix 7: Proof of Proposition 7}

$$
\begin{aligned}
\frac{d T^{*}}{d C} & =-\frac{\frac{d G}{d C}}{\frac{\partial G}{\partial T}}=\frac{-1}{\frac{\lambda}{\lambda-1}\left(r-\alpha_{i}\right) C_{i} e^{r T}-\left(\delta_{i}-\frac{1}{2} \sigma_{i}^{2}\right) \tilde{P}_{i}(0) e^{\left(\delta_{i}-\frac{1}{2} \sigma_{i}^{2}\right) T}}\left[\frac{\lambda}{\lambda-1}\left(r-\alpha_{i}\right) \frac{1}{r} e^{r T}-\frac{\lambda}{\lambda-1}\left(r-\alpha_{i}\right) \frac{1}{r}\right] \\
& =\frac{-1}{\frac{\lambda}{\lambda-1}\left(r-\alpha_{i}\right) C_{i} e^{r T}-\left(\delta_{i}-\frac{1}{2} \sigma_{i}^{2}\right) \tilde{P}_{i}(0) e^{\left(\delta_{i}-\frac{1}{2} \sigma_{i}^{2}\right) T} \frac{\lambda}{\lambda-1}\left(r-\alpha_{i}\right) \frac{1}{r}\left[e^{r T}-1\right]} \\
& =\frac{-1}{\left(e^{r T}-\frac{\left(\delta_{i}-\frac{1}{2} \sigma_{i}^{2}\right)(\lambda-1)}{\left(r-\alpha_{i}\right) \lambda} \frac{\tilde{P}_{i}(0)}{C_{i}} e^{\left(\delta_{i}-\frac{1}{2} \sigma_{i}^{2}\right) T}\right) \frac{\lambda\left(r-\alpha_{i}\right)}{\lambda-1} C_{i}} \frac{\lambda}{\lambda-1}\left(r-\alpha_{i}\right) \frac{1}{r}\left[e^{r T}-1\right] \\
& =\underbrace{\frac{-\left[e^{r T}-1\right]}{\left.e^{r T}-\frac{\left(\delta_{i}-\frac{1}{2} \sigma_{i}^{2}\right)(\lambda-1)}{\left(r-\alpha_{i}\right) \lambda} \frac{\tilde{P}_{i}(0)}{C_{i}} e^{\left(\delta_{i}-\frac{1}{2} \sigma_{i}^{2}\right) T}\right)} r C_{i}}_{<0 \text { see (22 and 16) }}>0
\end{aligned}
$$

